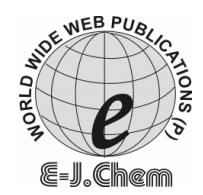

http://www.e-journals.net
ISSN: 0973-4945; CODEN ECJHAO

E-Journal of Chemistry 2010, 7(2), 445-448

\title{
Spectrophotometric Method for the Determination of Nebivolol Hydrochloride in Bulk and Pharmaceutical Formulations
}

\author{
A. LAKSHMANA RAO*, K.R. RAJESWARI and G.G. SANKAR \\ Department of Pharmaceutical Analysis, \\ Shri Vishnu College of Pharmacy, Vishnupur, Bhimavaram - 534 202, A.P., India. \\ dralrao@gmail.com
}

Received 11 September 2009; Accepted 5 November 2009

\begin{abstract}
A simple, sensitive, highly accurate spectrophotometric method in UV region has been developed for the determination of nebivolol hydrochloride in bulk and pharmaceutical formulations. Nebivolol hydrochloride is an antihypertensive drug, which shows maximum absorbance at $281 \mathrm{~nm}$ with apparent molar absorptivity of $5.37208 \times 10^{3} \mathrm{~mol}^{-1} \mathrm{~cm}^{-1}$. Beer's law was obeyed in the concentration range of $4-60 \mu \mathrm{g} / \mathrm{mL}$. The slope, intercept and correlation coefficient were also calculated. The proposed method has been successfully used for the analysis of the drug in pure and its tablet dosage forms. Results of percentage recovery shows that the method was not affected by the presence of common excipients. The percentage assay of nebivolol hydrochloride was 98.75 and 99.02 respectively. The method was validated by sensitivity and precision which proves suitability of proposed method for the routine estimation of nebivolol in bulk and pharmaceutical formulations.
\end{abstract}

Keywords: Nebivolol, Spectrophotometry, Estimation, Tablets.

\section{Introduction}

Nebivolol hydrochloride chemically ${ }^{1},( \pm)\left[2 \mathrm{R}^{*}\left[\mathrm{R}^{*}\left[\mathrm{R}^{*}\left(\mathrm{~S}^{*}\right)\right]\right]\right]-\alpha, \alpha^{\prime}$-[iminobis(methylene) $]$ bis[6-fluoro-3,4-dihydro-2H-1-benzopyran-2-methanol] hydrochloride, a new antihypertensive drug, is a racemate of two enantiomers with four chiral centres. The mechanism action of nebivolol is a competitive and highly selective $\beta_{I^{-}}$receptor antagonist and does not show an intrinsic sympathomimetic activity. Nebivolol is endowed with peripheral vasodilating properties mediated by the modulation of the endogenous production of nitric oxide and thus lowers peripheral resistance. The SRRR- enantiomer ( $d$-nebivolol) is a potent and cardioselective $\beta_{1}$-adrenergic blocker. The RSSS- enantiomer (l-nebivolol) has a favourable hemodynamic profile, in that normal energy supply during exercise is nor affected ${ }^{2-4}$. 


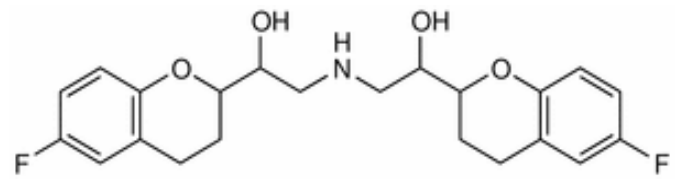

Figure 1. Structure of nebivolol.

Literature survey reveals that various HPLC $^{5-8}$ and LC-MS ${ }^{9-10}$ methods have been reported for the estimation of nebivolol in pure and tablet dosage forms. The present investigation reports a simple UV spectrophotometric method for the analysis of nebivolol in bulk as well as in tablet dosage form.

\section{Experimental}

Nebivolol hydrochloride was obtained as a gift sample from M/s. Cadila Pharmaceuticals Ltd., Ahmedabad. All the chemicals were of analytical reagent grade of S.D. Fine Chemicals, Mumbai. Double distilled water was used to prepare all solutions. Freshly prepared solutions were always employed. Different brands of tablets of nebivolol hydrochloride were purchased from local market.

\section{Instrumentation}

ELICO-SL 164 double beam UV-Visible spectrophotometer with $1 \mathrm{~cm}$ matched quartz cells was used.

\section{Preparation of stock solution}

Nebivolol equivalent to nebivolol hydrochloride was weighed accurately and dissolved in methanol so as to give stock solution of concentration of $1000 \mu \mathrm{g} / \mathrm{mL}$.

\section{Method development}

Aliquots of $100 \mu \mathrm{g} / \mathrm{mL}$ solution were transferred into nine $10 \mathrm{~mL}$ volumetric flasks and volume was adjusted with distilled water to give final concentrations of 4, 6, 8, 10, 20, 30, 40, $50,60 \mu \mathrm{g} / \mathrm{mL}$. The absorbance was measured at $281 \mathrm{~nm}$ against distilled water as a blank. A calibration graph of the absorbance versus the concentration of the drug was plotted.

\section{Procedure for calibration curve}

Aliquots of stock solution were further diluted with distilled water to get working solution of 4 , $6,8,10,20,30,40,50$ and $60 \mu \mathrm{g} / \mathrm{mL}$. Finally, the prepared standards were measured after standing for $5 \mathrm{~min}$. at $\lambda_{\max }$ as recorded in each case against a solvent blank similarly prepared. A calibration graph of the absorbance versus the concentration of the drug was plotted.

\section{Procedure for dosage forms}

For analysis of commercial formulations, twenty tablets were taken and powdered. Tablet powder equivalent to $5 \mathrm{mg}$ of nebivolol was transferred into a $50 \mathrm{~mL}$ volumetric flask and dissolved in small quantity of methanol. Then the solution was sonicated for $30 \mathrm{~min}$. and filtered. The filtrate was further diluted with distilled water to get required concentration. The absorbance was measured at $281 \mathrm{~nm}$ against distilled water as a blank.

\section{Recovery study}

Recovery studies were carried out by adding a known quantity of pure drug to the preanalysed formulations and the proposed method was followed. From the amount of drug found, percentage recovery was calculated. 


\section{Results and Discussion}

The absorption spectrum of nebivolol hydrochloride was measured in the range of 200-400 $\mathrm{nm}$ against the blank similarly prepared. The standard solution show maximum absorbance at $\lambda_{\max }$ as recorded. The proposed method was validated by studying the following parameters as per ICH guidelines for method validation. The proposed method of determination of nebivolol hydrochloride showed molar absorptivity of $5.37208 \times 10^{3} \mathrm{~mol}^{-1} . \mathrm{cm}^{-1}$. Linear regression of absorbance on concentration gave the equation $y=0.0006829+0.0142 x$ with a correlation coefficient of 0.99984 . Relative standard deviation of $<1 \%$ was observed for analysis of five replicate samples, indicating precision and reproducibility. Nebivolol hydrochloride exhibits its maximum absorption at $281 \mathrm{~nm}$ and obeyed Beer's law in the concentration range of 4-60 $\mu \mathrm{g} / \mathrm{mL}$. The results of analysis are presented in Table 1 .

Table 1. Results of assay.

\begin{tabular}{ccccc}
\hline Formulation & $\begin{array}{c}\text { Label } \\
\text { claim, mg }\end{array}$ & $\begin{array}{c}\text { Amount found } \\
\mathrm{mg}\end{array}$ & $\begin{array}{c}\text { \% Amount } \\
\text { found }\end{array}$ & \% C.V. \\
\hline Brand-1 & 5.0 & $4.935 \pm 0.0492$ & 98.75 & 0.9997 \\
Brand-2 & 5.0 & $4.951 \pm 0.0687$ & 99.02 & 1.002 \\
\hline
\end{tabular}

*Mean of five determinations.

Accuracy of the method was performed by recovery studies. The percentage recovery value indicates that there is no interference from the excipients present in the formulation. The recovery studies are presented in Table 2 . The specificity of the method was conducted to prove that they are free from determined interference of solvent and commonly used tablet excipients. This is evidenced by the lack of absorbance at the specified $\lambda_{\max }$ for the excipients in the blank solutions. The applicability of the proposed method for the assay of nebivolol in tablet formulation was examined by analyzing commercial formulations and the results are tabulated. The result obtained were good agreement with the label claims. The results of analysis of the commercial tablets and the recovery study of the drug suggested that there is no interference from any excipients such as starch, lactose, magnesium stearate etc. which are commonly present in tablets.

Table 2. Recovery studies.

\begin{tabular}{ccccc}
\hline S. No. & $\begin{array}{c}\text { Label claim, } \\
\text { mg/tablet }\end{array}$ & $\begin{array}{c}\text { Amount of } \\
\text { standard added, mg }\end{array}$ & $\begin{array}{c}\text { Total amount } \\
\text { recovered, mg }\end{array}$ & $\begin{array}{c}\% \\
\text { Recovery }\end{array}$ \\
\hline 1 & 5 & 0 & 4.92 & 98.4 \\
2 & 5 & 10 & 15.04 & 100.2 \\
3 & 5 & 20 & 24.96 & 99.8 \\
4 & 5 & 30 & 35.10 & 100.2 \\
5 & 5 & 40 & 45.16 & 100.3 \\
\hline
\end{tabular}

\section{Conclusion}

The developed method is found to be sensitive, accurate and reproducible and can be used for the routine quality control analysis of nebivolol hydrochloride in bulk and pharmaceutical formulations.

\section{Acknowledgment}

The authors are thankful to M/s. Cadila Pharmaceuticals Ltd., Ahmedabad for providing gift sample of nebivolol hydrochloride and also management of Shri Vishnu College of Pharmacy for providing necessary facilities to carry out the research work successfully. 


\section{References}

1. The Merck Index, $13^{\text {th }}$ Ed.., Merck \& Co., Inc., Whitehouse Station, NJ, 2001, p.1152.

2. Pauwels P J, Gommeren W, Van Lommen G, Janssen P A and Leysen J E, Mol Pharmacol., 1988, 34, 843-851.

3. Xhonneux R, Wouters L, Reneman R S and Janssen P A J, Eur J Pharmacol., 1990, 181(3), 261-265.

4. Van De Water A, Xhonneux R, Reneman R S and Janssen P A J, Eur J Pharmacol., 1988, 156(1), 95-103.

5. Sastry B S, Srinivasulu D and Ramana H, J Pharmaceut Res Health Care, 2009, 1(1), 25-33.

6. Sahoo M K, Giri M K, Barik C S, Kanungo S K and Ravi Kumar B V V, E-Journal of Chemistry, 2009, 6(3), 915-919.

7. Hassan Y, Aboul-Enein and Imran Ali, J Biochem Biophy Methods, 2001, 48(2), 175-188.

8. Hendrickx J, Bockx M, Zwijsen C, Borgmans C, Mannens G, Meuldermans W and Heykants J, J Chromatogr A, 1996, 729(1-2), 341-354.

9. Senthamil Selvan P, Veeran Gowda K, Mandal U, Sam Solomon W D and Pal T K, $J$ Chromatogr B, 2007, 858(1-2), 143-150.

10. Ramakrishna N V S, Vishwottam K N, Koteshwara M, Manoj S, Santosh M and Varma D P, J Pharm Biomed Anal., 2005, 39(5), 1006-1013. 


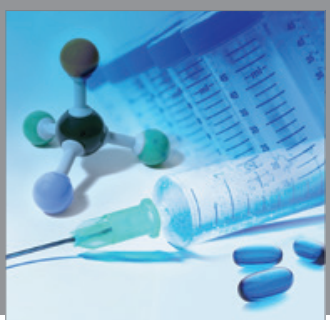

International Journal of

Medicinal Chemistry

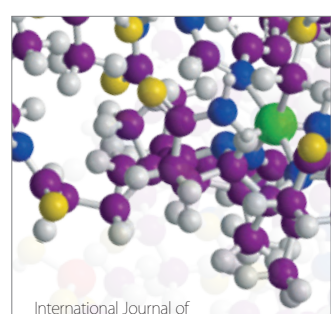

Carbohydrate Chemistry

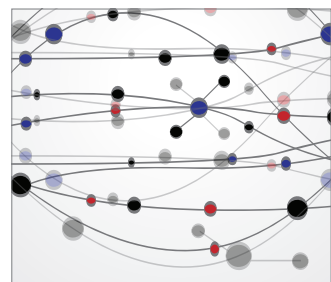

The Scientific World Journal
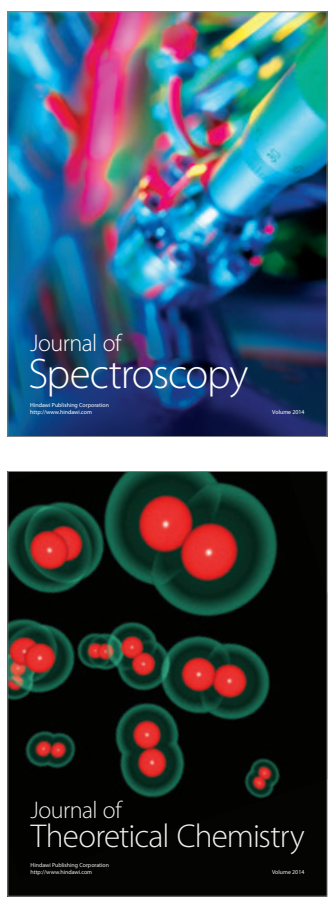
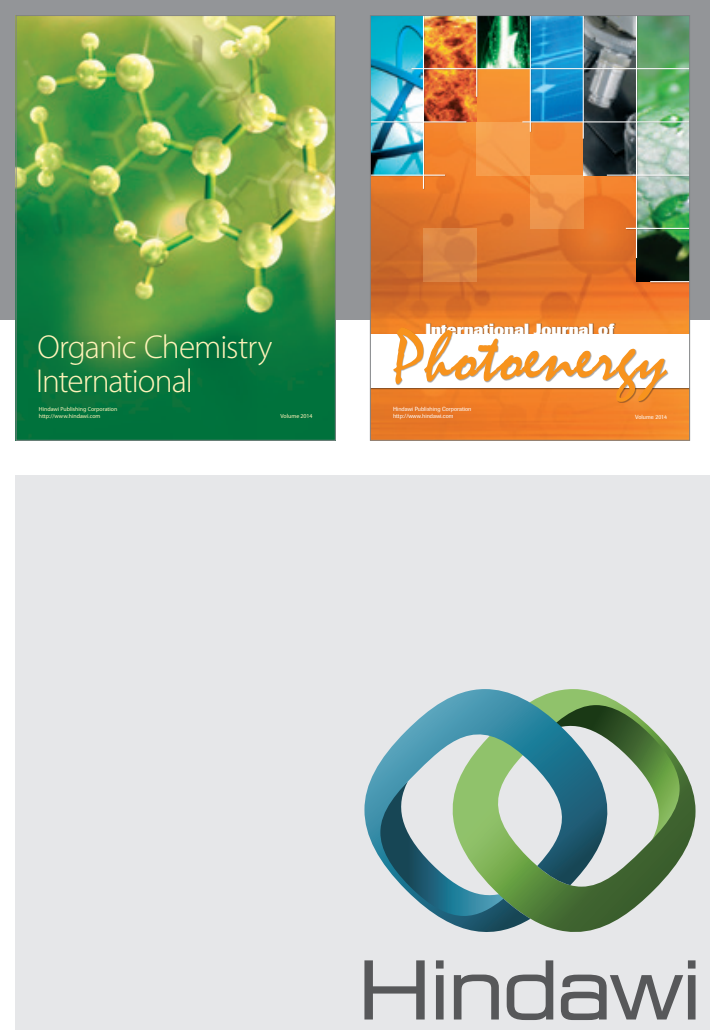

Submit your manuscripts at

http://www.hindawi.com
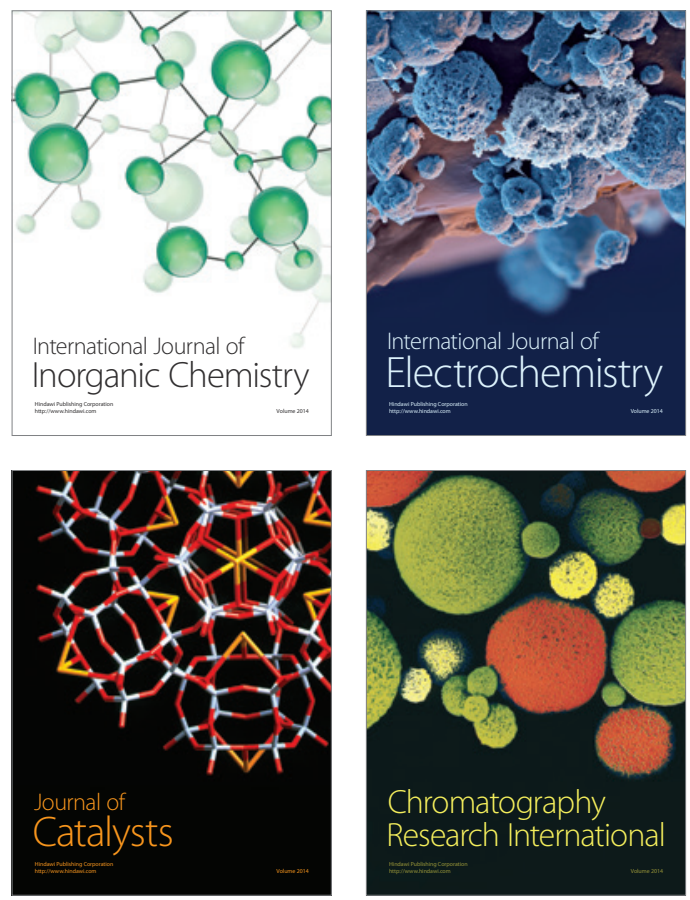
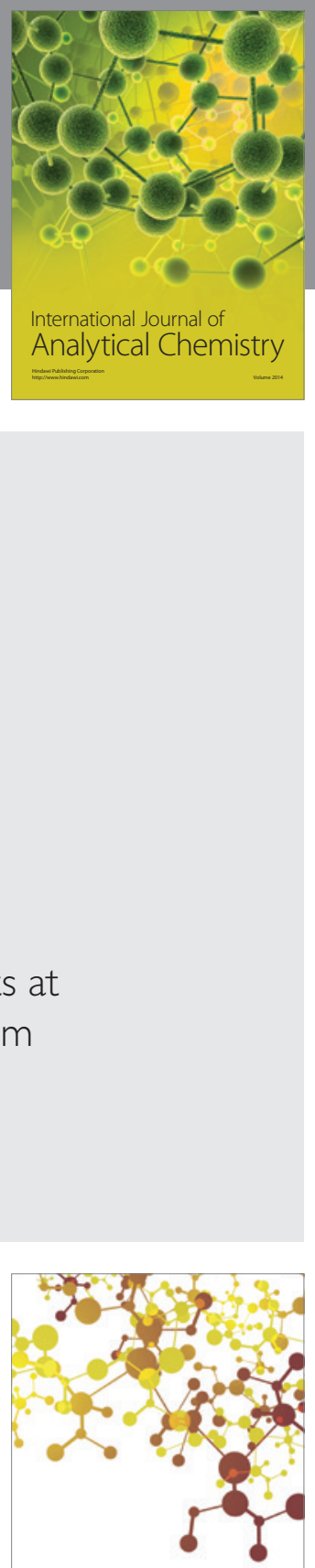

Journal of

Applied Chemistry
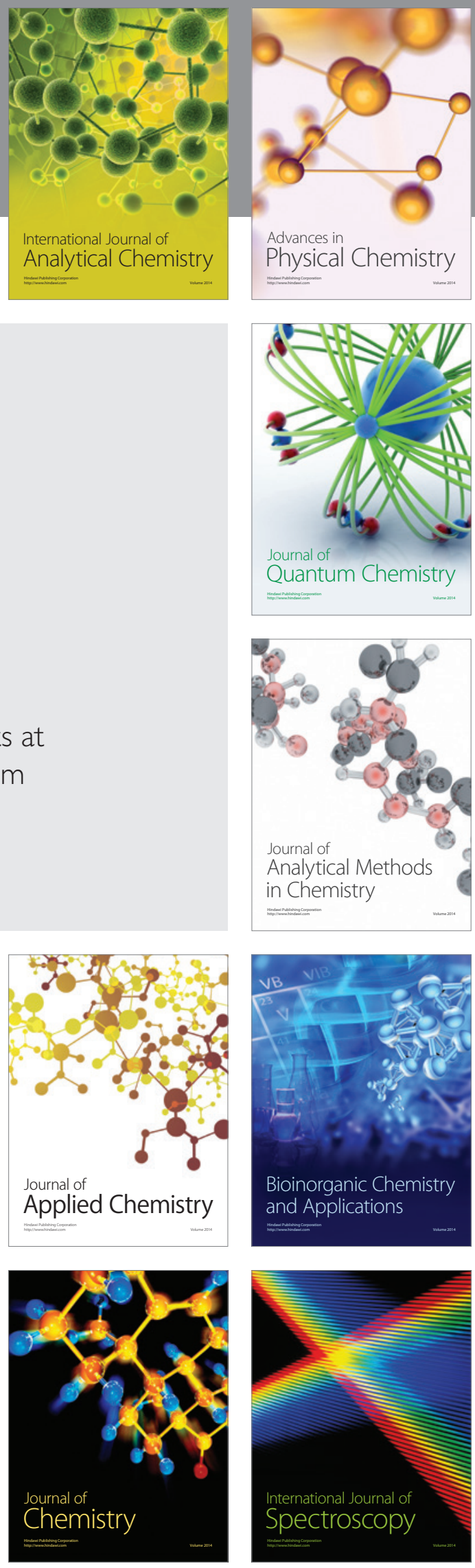